\title{
Connect the drops
}

\author{
The world's inland waters are under siege. A system-level view of watersheds is needed to inform both \\ our scientific understanding and management decisions for these precious resources.
}

It should not need to be said that water is an important resource. After all, it is a necessity for life as we know it. And yet, while we scheme to harness small amounts of water ice on the Moon to fuel future moonbases and marvel at evidence for mere traces of the liquid on Mars, many of our own water resources here on Earth are being dirtied and depleted. Small water bodies in headwater systems are particularly vulnerable, despite significant repercussions downstream due to the connections within watersheds. A web focus published alongside this issue (https://www. nature.com/collections/pzcfnxjvfb) explores the many functions that inland waters provide to ecosystems and the threats they face as a result of humanity's actions - mainly climate change and increasing human activities.

Aquatic systems inland are composed of all number of combinations of rivers, lakes, streams, intermittent creeks, wetlands and the smallest of ponds. They transport not only water, but sediment, nutrients, biota and contaminants both within and between water bodies. Such exchange occurs along flow pathways that are both lateral across landscapes and vertical between subsurface and surface.

Inland waters provide a plethora of hydrological, chemical and biological functions in watersheds. For example, in this issue, Evans and colleagues (page 832) report on how inland waters mediate the transport of organic carbon from land to ocean due to reactions with sunlight. They find that organic carbon reactivity is regulated by trophic status and residence time. And, hidden from sunlight beneath an ice sheet, Overeem et al. (page 859) demonstrate that Greenland's subglacial streams contribute significantly to the global sediment export to the oceans.

Although it is clear that inland aquatic systems play an important role in the health of watersheds, Creed and co-workers (page 809) argue that these waters are susceptible to destruction and degradation. Intermittent streams and seemingly isolated wetlands are particularly vulnerable because they are often inadequately mapped or monitored and the connections between them and the rivers downstream are difficult to define. As a result, they are often only poorly protected by government policies, or indeed not at all.

It is not just freshwater that is under threat. Wurtsbaugh et al. (page 816) report

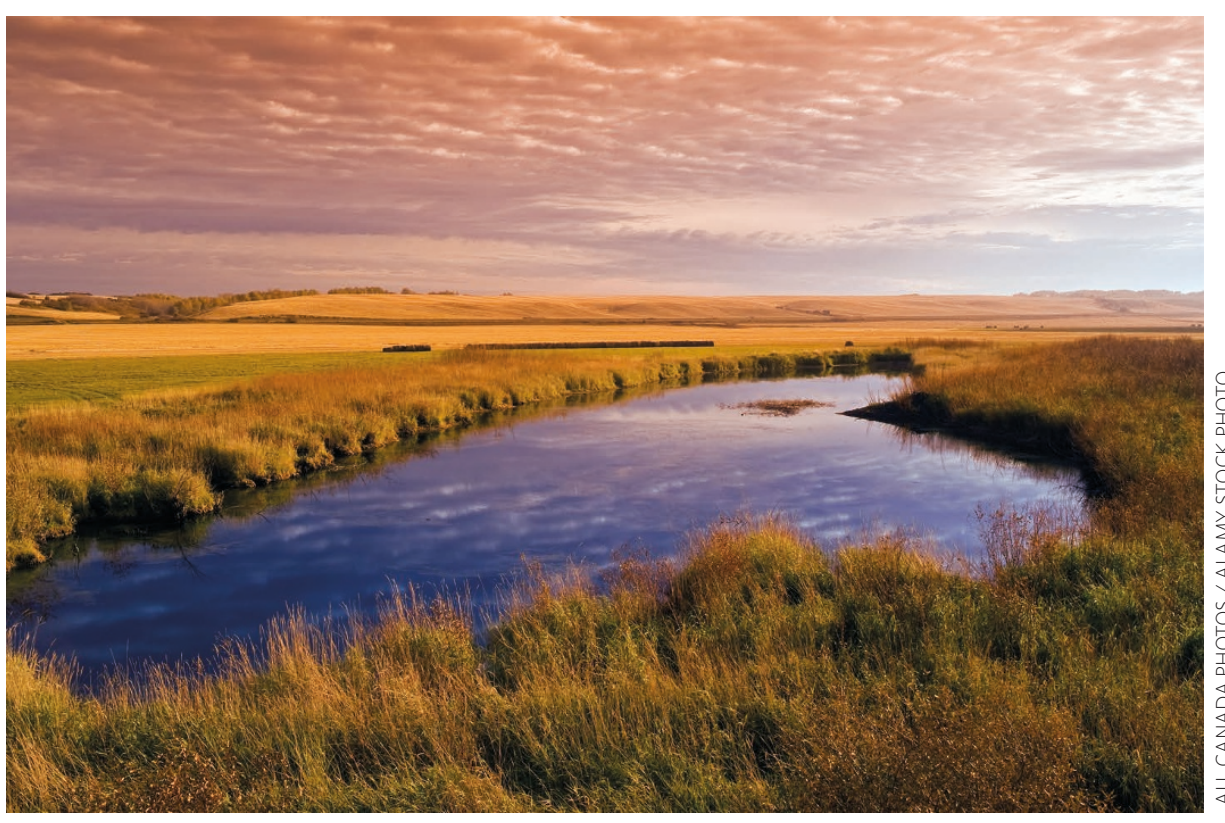

that many of the world's saline lakes have been shrinking, both due to changes in climate and human diversions of streamflow away from lakes for other uses. These waters too host ecosystems to which they provide a range of services. They also support human industries, such as mineral extraction and fishing.

Human overuse and climatic factors are leading to problems of water scarcity. Yet assessments of water scarcity are more complicated than simply measuring available volume: different indicators of water quality need to be considered too. For example, water temperature is key for cooling power plants, whereas salinity or pollutant content needs to be regulated for potability (van Vliet et al., page 800). And once we appreciate that upstream watershed conditions, such as vegetation cover, can have measurable consequences on human health (http://go.nature.com/2goSelq), it is not difficult to understand the importance of mitigating against the loss and pollution of our inland waters.

Determining how best to do so amidst a growing human population and ever developing world requires multidisciplinary approaches. We need to understand much better how aquatic systems work and connect to each other, and how best to protect them. 'Connectivity' is more than just a buzzword in inland-waters research, but key to providing the sort of information that is needed to manage aquatic systems, as was communicated at a conference on the topic in May 2017 (http://www.awra.org/meetings/ Snowbird2017/).

Creed and colleagues (page 809) make a valiant effort to provide viable policy options to protect the world's inland waters based on a wealth of scientific studies. But whether such efforts by scientists to use their science towards sustainable solutions will lead to action is less clear. Unfortunately, good science-based policy recommendations often run up against obstructive political realities, such as the ongoing political battle in the US over how to define which waters to protect against pollution, as discussed by Mark Ryan on page 807 .

We hope that political dams can be breached by pushing forward scientific pursuits that combine hydrology, biogeochemistry and ecology as a means to understand the interconnected complexities of watersheds and inform policymakers. And we encourage policymakers to take a similarly holistic view of aquatic systems. Scientists and regulators may not speak the same language, but they need to at least operate within the same framework. 